\title{
Resistin Activates p65 Pathway and Reduces Glycogen Content through Keratin 8
}

\author{
Fengyun Wen (iD, ${ }^{1,2}$ Qiao Xia, ${ }^{2}$ Hui Zhang, ${ }^{1}$ Haipeng Shia, ${ }^{1}$ Amin Rajesh, ${ }^{3}$ Yanling Wu, ${ }^{2}$ \\ Yi Yang, ${ }^{2}$ and Zaiqing Yang $\mathbb{D}^{1}$ \\ ${ }^{1}$ College of Animal Science and Technology, Henan University of Science and Technology, Luoyang 471000, Henan, China \\ ${ }^{2}$ Key Laboratory of Agricultural Animal Genetics, Breeding and Reproduction of Ministry of Education, \\ College of Life Science and Technology, Huazhong Agricultural University, Wuhan 430070, Hubei, China \\ ${ }^{3}$ Department of Drug Discovery and Development, Harrison School of Pharmacy, Auburn University, 36849-5501 Auburn, \\ Alabama, USA \\ Correspondence should be addressed to Zaiqing Yang; wfydpf@163.com
}

Received 15 October 2019; Revised 28 February 2020; Accepted 11 April 2020; Published 18 May 2020

Academic Editor: Silvia Monticone

Copyright ( 12020 Fengyun Wen et al. This is an open access article distributed under the Creative Commons Attribution License, which permits unrestricted use, distribution, and reproduction in any medium, provided the original work is properly cited.

\begin{abstract}
Resistin is associated with metabolic syndrome and inflammatory conditions. Many studies have suggested that resistin inhibits the accumulation of glycogen; however, the exact mechanisms of resistin-induced decrease in glycogen content remain unclear. Keratin 8 is a typical epithelial intermediate filament protein, but numerous studies suggest a vital role of K8 in glucose metabolism. However, it is still not known whether K8 participates in the mediation of resistin-induced reduction of cellular glycogen accumulation. In this study, we found that resistin upregulated expression of the p65 subunit of NF- $\kappa \mathrm{B}$, which led to the promotion of K8 transcriptional expression; in turn, the expression of K8 inhibited glycogen accumulation in HepG2 cells.
\end{abstract}

\section{Introduction}

Resistin is one of the important cytokines secreted by adipocytes. It was discovered in 2001 [1] and regarded as the link between obesity and type II diabetes mellitus (T2DM). Resistin is expressed at higher levels in obese humans and mice than in lean controls $[2,3]$. Treatment with recombinant mouse resistin impaired the glucose tolerance and activity of insulin and induced hepatic insulin resistance [4]. Recombinant murine resistin significantly decreased glycogen content by decreasing the level of phosphorylated GSK-3 $\beta$ at Ser 9, leading to impaired hepatic insulin action [5]. Although many studies have attempted to clarify the mechanism of resistin-induced decrease in glycogen content, the relationship between resistin and glycogen remains unclear.

Keratin is a typical epithelial intermediate filament protein [6]. As a component of the epithelial cytoskeleton, keratin plays an important role in the maintenance of the stability and integrity of epithelial cells and tissues [7]. Some keratin proteins also serve as regulators in cell signaling pathways $[8,9]$. Keratins are also used as biomarkers in the diagnosis of cancer [10]. Studies on keratin 8 have shown that it is an essential member of the keratin family, which plays an important role in glucose metabolism $[9,11]$. Although problems with the uptake of glucose and its metabolites in hepatocytes are mainly attributed to chronic insulin-related disease, there is also evidence supporting a correlation between diabetes and various malignant tumors [12-15]. A similar correlation exists between glycogen storage disease and liver cell abnormality. The deletion of K8/K18 from hepatocytes promotes insulin-induced glycogen accumulation. Under high-glucose culture conditions, deletion or knockdown of K8/K18 in hepatocyte and hepatocellular carcinoma cells (HCCs) significantly promotes glycogen accumulation [9]. Other studies have found that K8 acetylation promotes perinuclear keratin filament organization. Acetylation also modulates K8 site-specific phosphorylation, a modification that is closely related to its solubility [16]. It is worth noting that the filament 
organization of $\mathrm{K} 8$ is regulated by glucose concentration [17]. In summary, the available data suggest a vital role of K8 in glucose metabolism. However, it is still not known whether K8 mediates resistin-induced reduction of cellular glycogen accumulation. In this study, we report that resistin upregulated p65, which inhibited the accumulation of glycogen in HepG2 cells by promoting the transcription of K8.

\section{Materials and Methods}

2.1. Materials. TRIzol reagent was purchased from Takara (Dalian, China), and Lipofectamine ${ }^{\mathrm{TM}} 2000$ was obtained from Invitrogen (Carlsbad, CA, USA). The antibody against the NF- $\kappa$ B p65 subunit was purchased from Santa Cruz Biotechnology (Santa Cruz, CA, USA). Recombinant human resistin was purchased from PeproTech, Inc. (Rocky Hill, NJ, USA). The glucose assay kit was purchased from Applygen Technologies Co., Ltd. (Beijing, China). Small interfering RNAs (siRNAs) were synthesized by IBS Bio (Shanghai, China). The Dual-Luciferase Assay kit was purchased from Promega (Madison, WI, USA). The Chromatin Immunoprecipitation (ChIP) Assay kit was from Millipore (Burlington, MA, USA).

2.2. Animal Experiment. Male C57BL/6J mice (8 weeks old) were purchased from Huafukang Biotech (Beijing, China) and housed in individual plastic cages at around $25^{\circ} \mathrm{C}$ under a $12: 12 \mathrm{~h}$ light-dark cycle with free access to water and food. Mice were divided into two groups (control and resistintreated), 6 mice for each group. All of the mice were put on a standard chow and water diet. Animals in the group treated with resistin received $400 \mathrm{ng}$ resistin daily for 6 days by injection via the vena caudalis [18]. After being fasted overnight, mice were sacrificed on day 7 , and the livers were collected immediately and snap frozen in liquid nitrogen and then stored at $-70^{\circ} \mathrm{C}$ before analysis. The Hubei Province Committee on Laboratory Animal Care approved all procedures.

2.3. Histology. Liver tissue samples $(n=6)$ were gathered $24 \mathrm{~h}$ after tail vein injection with or without resistin and fixed in $10 \%$ formalin solution. The samples were processed and embedded in paraffin. Hematoxylin and eosin (H\&E) staining was used to identify and describe the different tissues and structures within them. Rehydrated slides were rinsed for $1 \mathrm{~min}$ in distilled water, immersed in hematoxylin (Servicebio, China) for $5 \mathrm{~min}$, and rinsed in running tap water for $10 \mathrm{~min}$. The slides were then rinsed in $80 \%$ ethanol for $1 \mathrm{~min}$ and immersed in eosin (Servicebio) for $5 \mathrm{~min}$. Finally, the slides were dehydrated, cleared, and mounted with coverslips. Periodic acid-Schiff (PAS) staining was used to assess the glycogen content. Slides were rinsed in distilled water and immersed in PAS staining solution B (Servicebio) for $15 \mathrm{~min}$, rinsed with distilled water, and immersed in PAS staining solution A (Servicebio) for $30 \mathrm{~min}$. The slides were then rinsed in running tap water for $10 \mathrm{~min}$, counterstained with PAS staining solution C for $30 \mathrm{~s}$, rinsed, dehydrated, cleared, and mounted with coverslips.
2.4. Cell Culture. HepG2 (ATCC) cells were maintained in DMEM medium (HyClone, Thermo Scientific, Logan, UT, USA) supplemented with $10 \%$ fetal bovine serum (FBS) (Tianhang, Zhejiang, China), $100 \mathrm{U} / \mathrm{mL}$ penicillin, and $100 \mu \mathrm{g} / \mathrm{mL}$ streptomycin and cultured at $37^{\circ} \mathrm{C}$ in a humidified chamber containing $5 \% \mathrm{CO}_{2}$.

2.5. Vectors and Transfection. Expression vectors for $\mathrm{p} 65$ (pcDNA3.1-p65) were constructed by inserting the products of reverse transcription and PCR obtained from HepG2 RNA into pcDNA3.1. siRNAs for p65 and K8 were purchased from IBS (Shanghai, China). Unless otherwise indicated, all of the experiments were performed in three independent experiments, each in triplicate. Vectors and siRNAs were transfected into cells in a serum-free medium. The samples were prepared for transfection as follows: (A) to a $1.5 \mathrm{~mL}$ tube, we added $50 \mu \mathrm{L}$ opti-MEM medium, an appropriate amount of lipofectamine 2000, mixed gently, and left at room temperature for $5 \mathrm{~min}$. (B) To another $1.5 \mathrm{~mL}$ tube, we added $50 \mu \mathrm{L}$ opti-MEM medium and diluted plasmid DNA, mixed gently, and left the mixture at room temperature for $5 \mathrm{~min}$. (C) After $5 \mathrm{~min}$, we gently mixed A and $\mathrm{B}$ and incubated the mixture at room temperature for $30 \mathrm{~min}$ to form the DNA-lipofectamine 2000 complex. Cells for transfection were washed three times with serum-free medium for $20 \mathrm{~min}$, after which $100 \mu \mathrm{L}$ of the mixture containing the DNA-lipofectamine 2000 complex and $400 \mu \mathrm{L}$ opti-MEM were added. The cells were then incubated at $37^{\circ} \mathrm{C}$ for $6 \mathrm{~h}$, and then the medium exchanged for growth medium. The cells were harvested for $24 \mathrm{~h}$ after transfection to isolate RNA or protein.

2.6. RNA Isolation. Total RNA was extracted with Trizol reagent (Takara, Dalian, China). Briefly, $500 \mu \mathrm{L}$ Trizol reagent was added to each well in a 24 -well plate. Cells were collected and $200 \mu \mathrm{L}$ of chloroform was added to it and centrifuged at $12000 \mathrm{rpm}$ for $15 \mathrm{~min}$. Then, the upper phases were collected, and equal volumes of isopropanol were added and centrifuged at $12000 \mathrm{rpm}$ for $10 \mathrm{~min}$. The precipitate was washed twice with $500 \mu \mathrm{L}$ of $75 \%$ ethanol, centrifuged at $8000 \mathrm{rpm}$ for $5 \mathrm{~min}$, air-dried, dissolved with $30-50 \mu \mathrm{L}$ of DEPC water, and stored at $-80^{\circ} \mathrm{C}$. The RNA quality was assessed using a UV-Vis spectrophotometer (SMA4000). RNA was generally of high quality (an average $260 / 280$ ratio of 2.02 and an average $260 / 230$ ratio of 1.79 ).

2.7. cDNA Reverse Transcription. The following reaction mixture $(30 \mu \mathrm{L})$ was prepared in $1.5 \mathrm{~mL}$ tubes: RNA sample, $5 \mu \mathrm{L}$; oligo T18 (20 nmol/L), $3 \mu \mathrm{L}$; dNTP $(20 \mathrm{nmol} / \mathrm{L}), 3 \mu \mathrm{L}$; M-MLV reverse transcriptase, $0.5 \mu \mathrm{L}$; RNase inhibitor, $0.5 \mu \mathrm{L} ; 5 \times \mathrm{M}-\mathrm{MLV}$ buffer, $6 \mu \mathrm{L}$; and DEPC water, $12 \mu \mathrm{L}$. We incubated the mixture for $1 \mathrm{~h}$ at $42^{\circ} \mathrm{C}$ and $90^{\circ} \mathrm{C}$ for $10 \mathrm{~min}$ to stop the reaction and stored the sample at $-20^{\circ} \mathrm{C}$.

2.8. Quantitative Real-Time PCR. For real-time PCR, we followed the method of Wen et al. [19]. The sequences of the primers used for qRT-PCR are listed in Table 1. 
TABLE 1: The primers for real-time PCR amplifications.

\begin{tabular}{|c|c|c|c|}
\hline Gene name & Sequence & Size (bp) & Accession number \\
\hline Homo GAPDH & $\begin{array}{l}\text { F: TGCACCACCAACTGCTTAGC } \\
\text { R: GGCATGGACTGTGGTCATGAG }\end{array}$ & 147 & NM_002046 \\
\hline Homo p65 & $\begin{array}{c}\text { F: ATCCCATCTTTGACAATCGTGC } \\
\text { R: CGTGAAATACACCTCAATGTCCTC }\end{array}$ & 146 & NM_021975 \\
\hline Homo Keratin 8 & $\begin{array}{c}\text { F: GCCGTGGTTGTGAAGAA } \\
\text { R: CTGTTCCCAGTGCTACCCT } \\
\end{array}$ & 165 & NM_001256282.1 \\
\hline Homo GP & $\begin{array}{l}\text { F: TGATGGCAGCCACTCTACGA } \\
\text { R: TCACAGTCCGAGGCACAAAA }\end{array}$ & 97 & AH002957 \\
\hline Homo GS & $\begin{array}{l}\text { F: ACAAGCAGTGCGAAAACAGC } \\
\text { R: CATGTTGTGCGTGGTCACTG }\end{array}$ & 199 & S70004 \\
\hline Homo GSK $3 \beta$ & $\begin{array}{l}\text { F: GCAGCAAGGTGACAACAGTG } \\
\text { R: GGCGACCAGTTCTCCTGAAT }\end{array}$ & 149 & NM_002093 \\
\hline Mus GP & $\begin{array}{l}\text { F: CCTTCGCCTACACCAACCAC } \\
\text { R: TGCGGCTGATGTCTTTAGGA }\end{array}$ & 162 & NM_133198.2 \\
\hline Mus GS & $\begin{array}{l}\text { F: AGGACATTTCAGGGATTAA } \\
\text { R: CGTCTACCTCTACCTACCG }\end{array}$ & 176 & NM_030678.3 \\
\hline Mus GSK3 $\beta$ & $\begin{array}{l}\text { F: ACCCTCATTACCTGACCTT } \\
\text { R: TCGGCAGACAATTCAACTC }\end{array}$ & 154 & NM_019827.7 \\
\hline
\end{tabular}

2.9. Luciferase Assays. Cells were seeded into 24-well plates at a concentration of $1.0 \sim 2.5 \times 10^{3}$ cells and allowed to grow overnight. When it comes up to $80 \%$ confluency, the cells were incubated in serum-free DMEM for $6 \mathrm{~h}$ before transfection. We cotransfected the recombinant vector (pGL3-K8 promoter) or empty vector (pGL3-basic) with p65-expression plasmids (pcDNA3.1-p65) into the cells using Lipofectamine 2000 (Invitrogen) following the manufacturer's protocol. The pGL3-basic vector, containing the Firefly luciferase reporter, was used for normalization. After $24 \mathrm{~h}$, Firefly and Renilla luciferase activities were measured consecutively using the dual-luciferase assay. Three independent experiments were performed each in triplicate.

2.10. Measurement of Glucose and Glycogen Content. The glucose concentration in the medium was assayed using the Glucose Assay kit (Applygen). Absorbance was measured at $500 \mathrm{~nm}$ using a Beckman Coulter DU 800 UV-visible spectrophotometer. All of the samples were normalized to the total amount of protein. The glycogen level in each group was assessed using a glycogen assay kit (Nanjing Jiancheng Bioengineering Institute, China), and the results were normalized to a standard curve and expressed as milligrams of glycogen per milliliter of protein, as per the manufacturer's instructions.

2.11. Chromatin Immunoprecipitation. Chromatin immunoprecipitation (ChIP) assays were performed using Chromatin Immunoprecipitation Kits (Millipore) according to the manufacturer's instructions. Briefly, HepG2 cells were seeded $24 \mathrm{~h}$ before and fixed with $1 \%$ formaldehyde for 15-20 min to crosslink the chromatin; the reaction was then stopped by adding glycine to a final concentration of $0.125 \mathrm{M}$. The cells were disaggregated by homogenizing, passed through a $200 \mu \mathrm{m}$ pore filter, and centrifuged at $1000 \mathrm{rpm}$ for $5 \mathrm{~min}$ at $4^{\circ} \mathrm{C}$. The cell pellets were resuspended in $500 \mu \mathrm{L}$ cell lysis buffer and $2.5 \mu \mathrm{L}$ protease inhibitor, incubated on ice for $15 \mathrm{~min}$, and centrifuged at $800 \mathrm{~g}$ for $5 \mathrm{~min}$ at $4^{\circ} \mathrm{C}$. The supernatants were discarded, and the cells were resuspended in $500 \mu \mathrm{L}$ nuclear lysis buffer and $2.5 \mu \mathrm{L}$ protease inhibitor. The cells were then sonicated to break the DNA into 200-1000 bp fragments, followed by $10,000 \mathrm{~g}$ centrifugation for $10 \mathrm{~min}$ at $4^{\circ} \mathrm{C}$ to remove insoluble substances. For each IP reaction, we prepared a mixture in a $1.5 \mathrm{~mL}$ tube as follows: dilution buffer, $450 \mu \mathrm{L}$; protease inhibitor, $2.25 \mu \mathrm{L}$; DNA fragments, $50 \mu \mathrm{L}$; primary antibody, $2 \mu \mathrm{g}$; and protein $\mathrm{G}$ magnetic beads, $20 \mu \mathrm{L}$. We incubated the samples at $4^{\circ} \mathrm{C}$ overnight with constant rotation and collected the protein G-antibody complex magnetically and removed the supernatants the next day. We washed the protein $\mathrm{G}$ with $500 \mu \mathrm{L}$ of low-salt immune complex wash buffer, high-salt immune complex wash buffer, $\mathrm{LiCl}$ immune complex wash buffer, and TE buffer, respectively. We added $100 \mu \mathrm{L}$ of ChIP elution buffer and $1 \mu \mathrm{L}$ of protease $\mathrm{K}$ and incubated at $62^{\circ} \mathrm{C}$ for $2 \mathrm{~h}$ and then at $95^{\circ} \mathrm{C}$ for $10 \mathrm{~min}$. We transferred the protein $\mathrm{G}$ complex to a new tube, added $500 \mu \mathrm{L}$ of binding reagent $\mathrm{A}$, applied the sample on a column with a collection tube, and centrifuged at $10,000 \mathrm{~g}$ for $30 \mathrm{~s}$. We then washed the column with $500 \mu \mathrm{L}$ of wash buffer $\mathrm{B}$ and eluted with $50 \mu \mathrm{L}$ of elution buffer $\mathrm{C}$. We purified the DNA for use as the template for PCR. The PCR was carried out under the following conditions: $95^{\circ} \mathrm{C}$ for $5 \mathrm{~min}$ followed by 30 cycles of $20 \mathrm{~s}$ at $94^{\circ} \mathrm{C}, 30 \mathrm{~s}$ at $60^{\circ} \mathrm{C}$, and $30 \mathrm{~s}$ at $72^{\circ} \mathrm{C}$ and a $5 \mathrm{~min}$ final extension at $72^{\circ} \mathrm{C}$. The primers used for ChIP assay are listed in Table 2.

2.12. Statistical Analysis. Data are presented as mean$\mathrm{s} \pm$ standard deviation (SD). Statistical analyses were performed by GraphPad Prism 5.0 using the unpaired twotailed $t$-test (for two groups) and analysis of variance (ANOVA; for multiple groups). $P$ values $<0.05$ were considered to be statistically significant. 
TABle 2: Primers for ChIP assay.

\begin{tabular}{lcc}
\hline Name & Sequence $\left(5^{\prime} \longrightarrow 3^{\prime}\right)$ & Size $(\mathrm{bp})$ \\
\hline ChIP-p65-363 & $\begin{array}{l}\text { F: CCCTCAGTCTTTGTTATTCCTCG } \\
\text { R: CAGCACAGTATTCTCCTTTCCTA }\end{array}$ & 85 \\
\hline ChIP-p65-935 & $\begin{array}{l}\text { F: CCTACAGCATATCTGTTACGT } \\
\text { R: GGCAAGCTACTAGAACTCACT }\end{array}$ & 89 \\
\hline
\end{tabular}

\section{Results}

3.1. Resistin Downregulates Glycogen Levels Both in Liver and HepG2 Cells. In our previous study, the levels of blood glucose, insulin, and triglycerides were found to significantly increase in $\mathrm{C} 57 \mathrm{BL} / 6 \mathrm{~J}$ mice treated with resistin for six days [19]. In this study, we aimed to investigate the effects of resistin on glycogen storage.

Eight-week-old male C57BL/6J mice were treated with or without resistin, and glycogen in the liver was measured using the kit (Nanjing Jiancheng Bioengineering Institute, China). Liver tissue slices were stained with $\mathrm{H} \& \mathrm{E}$, which showed that there were more numerous and larger vacuoles in the hepatic cytoplasm of the resistin-treated group than in the control group (Figure 1(a)). PAS staining was used to assess the glycogen content directly. Both PAS staining and measurement of the glycogen content showed that the glycogen content was significantly decreased in the livers of resistin-treated mice compared with controls (Figures 1(a) and 1(b)).

To verify the result in vitro, we treated HepG2 cells with human recombinant resistin protein. The results showed that treatment of HepG2 cells with different concentrations of resistin for $24 \mathrm{~h}$ resulted in substantial inhibition of cellular glycogen accumulation. Although the accumulation amount of glycogen was inversely correlated with resistin dosage (Figure $1(\mathrm{c})$ ), even a low concentration $(25 \mathrm{ng} / \mathrm{mL})$ of resistin resulted in a significant reduction of glycogen levels.

Previous studies reported that resistin suppresses insulin-mediated cellular glucose uptake [20, 21]. To clarify whether the reduction in cellular glycogen content was due to resistin-mediated inhibition of cellular glucose uptake, we measured the glucose content in HepG2 cell medium $12 \mathrm{~h}$ after resistin treatment. The results showed that resistin did not significantly affect glucose uptake in the absence of insulin (Figure 1(d)), yet considerably lowered the glycogen content. These findings suggest that the action of resistin on glycogen accumulation is mediated through a mechanism other than lowering glucose uptake.

Furthermore, the expression of genes related to glycogen metabolism was examined in both mice and HepG2 cells treated with or without resistin using qRT-PCR. The results showed that glycogen synthase (GS) and glycogen kinase 3 beta $($ GSK-3 $\beta$ ) were significantly decreased in the treated mice liver and HepG2 cells, but the glycogen phosphorylase (GP) was not affected by resistin administration (Figures 1(e) and 1(f)).

3.2. Role of $K 8$ in Resistin-Regulated Glycogen Biosynthesis. Since previous data have suggested a vital role for $\mathrm{K} 8$ in glucose metabolism, we examined the interaction between resistin and $\mathrm{K} 8$ in regulating glycogen biogenesis. HepG2 cells were transfected with K8 siRNAs (Figure 2(a)), which resulted in a significant increase in glycogen accumulation after $24 \mathrm{~h}$ (Figure 2(b)). We then treated HepG2 cells with resistin for $24 \mathrm{~h}$ after $\mathrm{K} 8$ knockdown and measured the glycogen accumulation in the cells. Resistin significantly counteracted the increased glycogen accumulation caused by $\mathrm{K} 8$ ablation (Figure 2(c)). In summary, these findings indicate that inhibition of glycogen accumulation caused by resistin is partly due to the action of $\mathrm{K} 8$.

3.3. 765 Directly Binds to the K8 Promoter. To determine the mechanism whereby resistin regulates $\mathrm{K} 8$, we constructed a dual-luciferase reporter vector containing the K8 promoter (Figure 3(a)). We analyzed the $1635 \mathrm{bp} \mathrm{K8}$ promoter sequence using software from Genomatix (http://www. genomatix.de/) and identified potential transcription factor binding sites. A total of five $\mathrm{NF} \kappa \mathrm{B}$ binding sites were found on the K8 promoter, two of which partially overlapped and were subject to analysis as one site (Figure 3(b)). The p65 protein, a subunit of $\mathrm{NF}-\kappa \mathrm{B}$, is a nuclear transcription factor with roles in the regulation of many cellular processes. However, it is still not known whether it directly regulates $\mathrm{K} 8$ transcription. The dual-luciferase reporter vector containing the K8 promoter (pGL3-K8 promoter) or the empty vector (pGL3-basic) was transfected into the cells together with p65-expressing plasmids (pcDNA3.1-p65). A luciferase assay showed that p65 significantly enhanced K8 promoter activity (Figure 3(c)).

To further validate the direct binding of p65 to the K8 promoter, we conducted a ChIP assay. The results showed that p65 bound directly to the $-949 /-935$ and $-382 /-363$ sites on the $\mathrm{K} 8$ promoter region and regulated its transcription (Figure 3(d)).

3.4. Resistin Regulates K8 Transcription through p65. To determine whether p65 is involved in resistin-mediated transcriptional regulation of $\mathrm{K} 8$, we measured $\mathrm{K} 8$ expression in HepG2 cells treated with resistin and transfected with an expression plasmid for p65. Both p65 overexpression and resistin treatment were found to induce significant upregulation of K8 mRNA (Figures 4(a) and 4(b)). To verify that resistin regulates the transcription of $\mathrm{K} 8$ through $\mathrm{p} 65$, we transfected HepG2 cells with p65 siRNA (Figure 4(c)) and then treated the cells with resistin for $24 \mathrm{~h}$. Knockdown of p65 suppressed resistin-induced upregulation of K8 mRNA (Figure $4(\mathrm{~d})$ ), indicating that resistin regulated $\mathrm{K} 8$ transcription activity through p65.

3.5. P65 Is Involved in the Glycogen Accumulation Regulated by Resistin through K8. To clarify whether the downregulation of glycogen content by resistin is mediated through the binding of p65 to the promoter of K8, we first examined the effect of resistin on the levels of p $65 \mathrm{mRNA}$ and protein expression by using qRT-PCR and Western blot, respectively. The results were consistent with previous findings showing that resistin stimulated the p65 expression both at the mRNA level and protein level (Figures 5(a) and 5(b)). We then transfected 

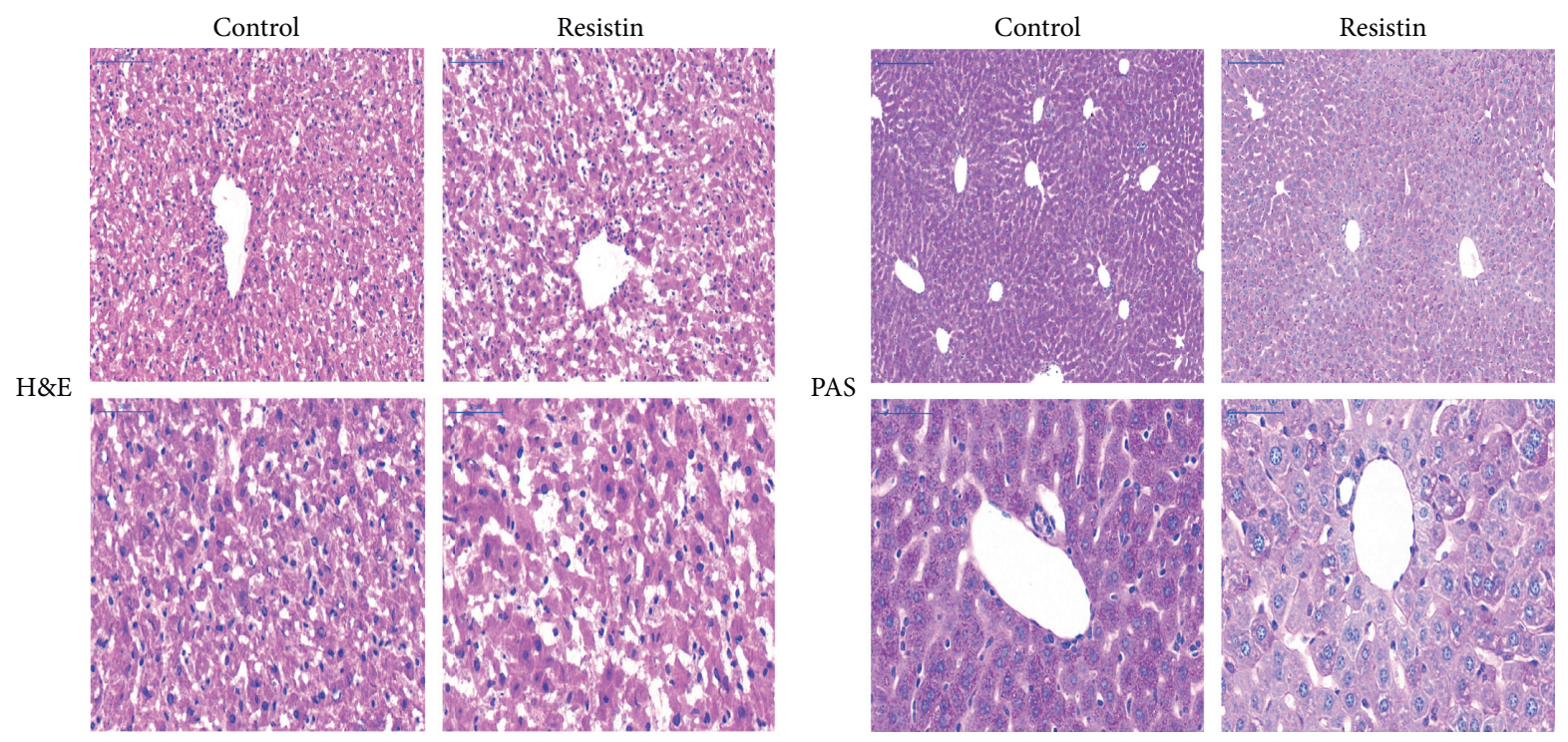

(a)

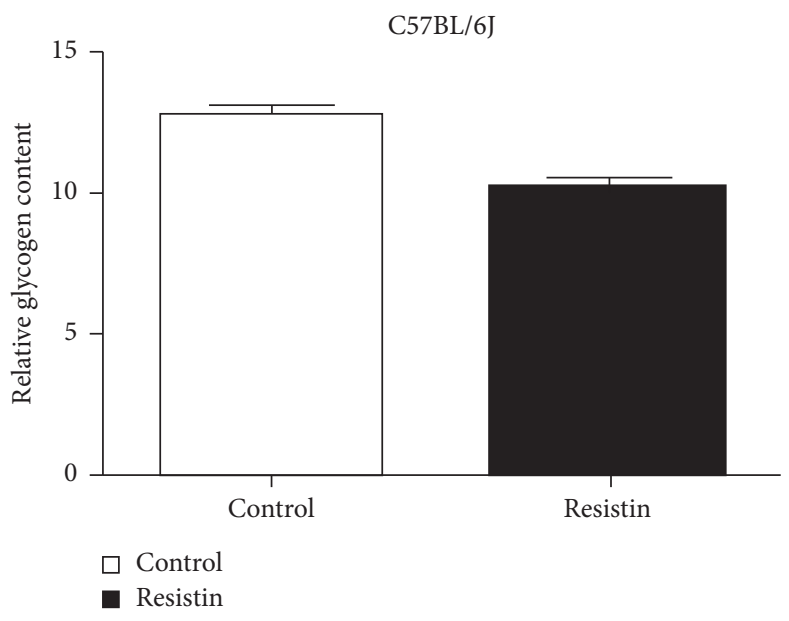

(b)

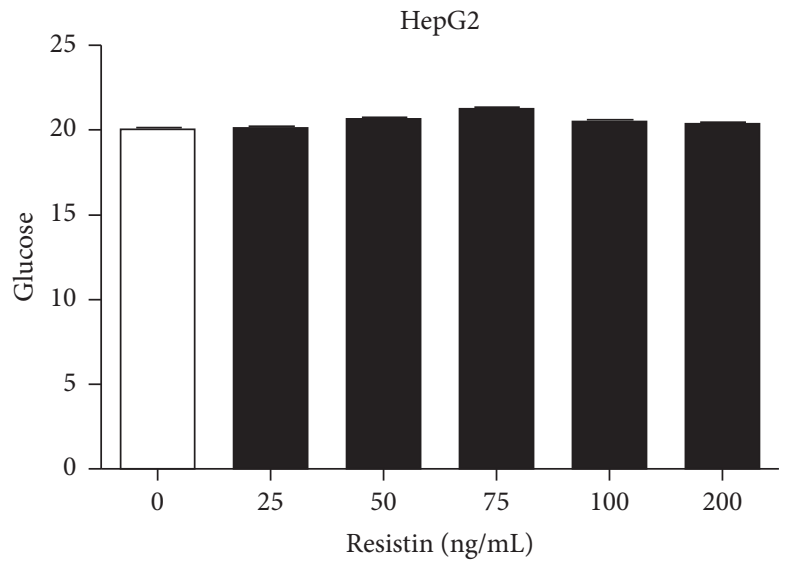

(d)

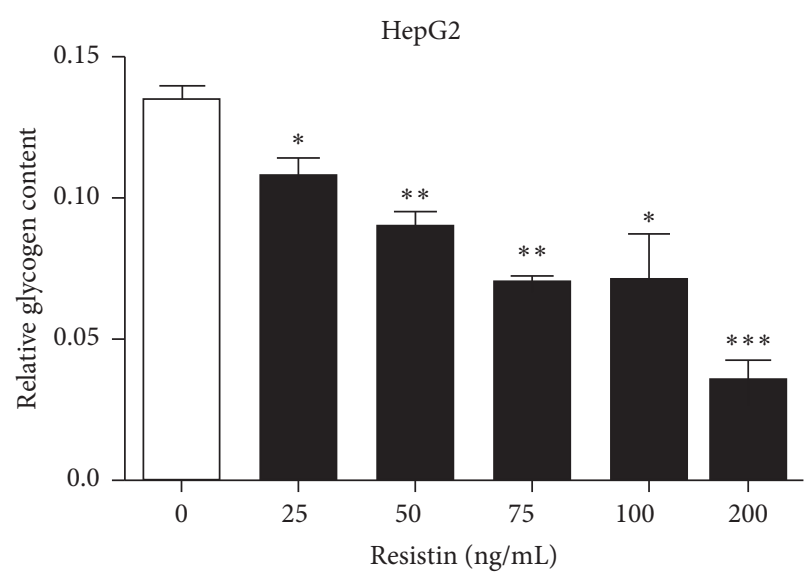

(c)

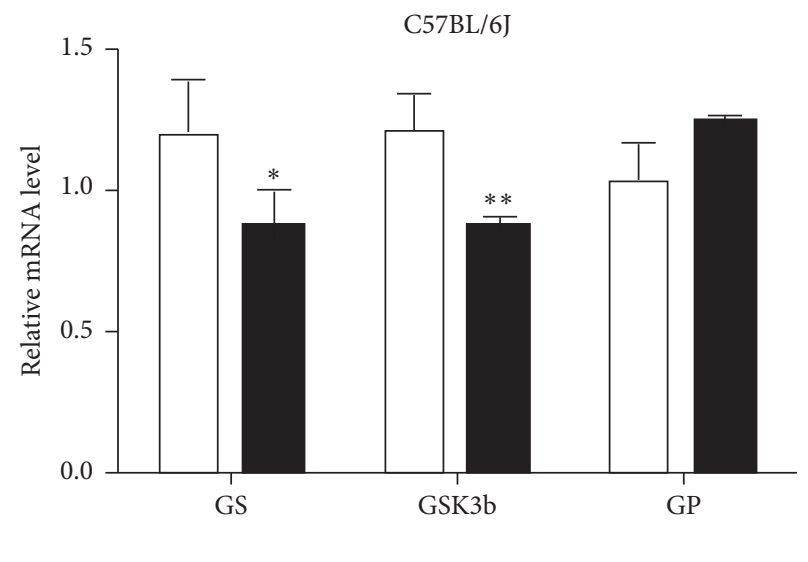

(e)

Figure 1: Continued. 


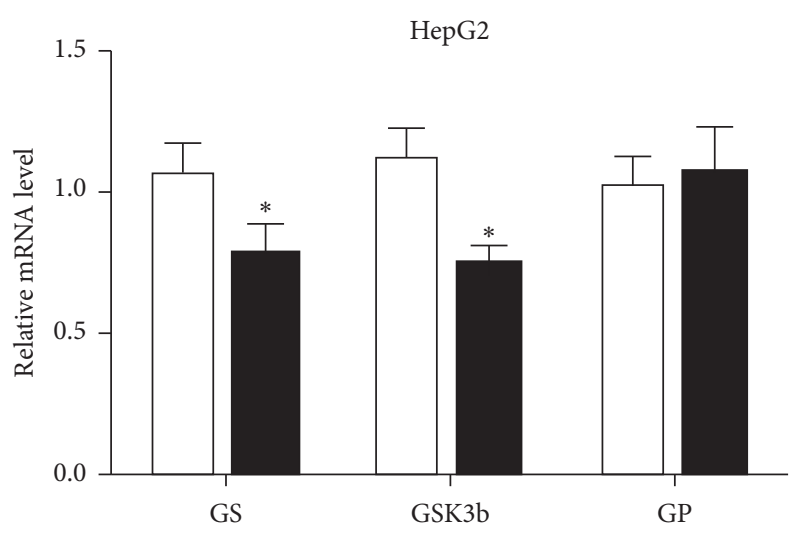

(f)

FIGURE 1: Resistin inhibits the production of glycogen. Eight-week-old male C57BL/6J mice were treated with or without resistin, and the PAS staining (a) and the glycogen content (b) measured by the glycogen assay kit (Nanjing Jiancheng Bioengineering Institute, China) were used to assess the glycogen content directly. HepG2 cells were treated with human recombinant resistin protein, and the glycogen content in cells (c) and glucose levels in the medium (d) measured. Eight-week-old male C57BL/6J mice (e) or HepG2 cells (f) were treated with or without resistin and the genes related to glycogen metabolism (GS, GSK3 $\beta$, and GP) were analyzed by using qRT-PCR. Data are presented as mean \pm SD. ${ }^{*} p<0.05$ and ${ }^{* *} p<0.01$.

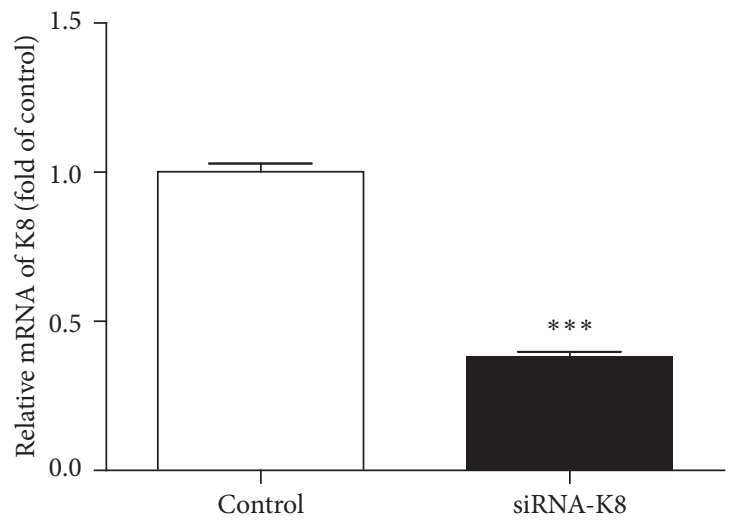

(a)

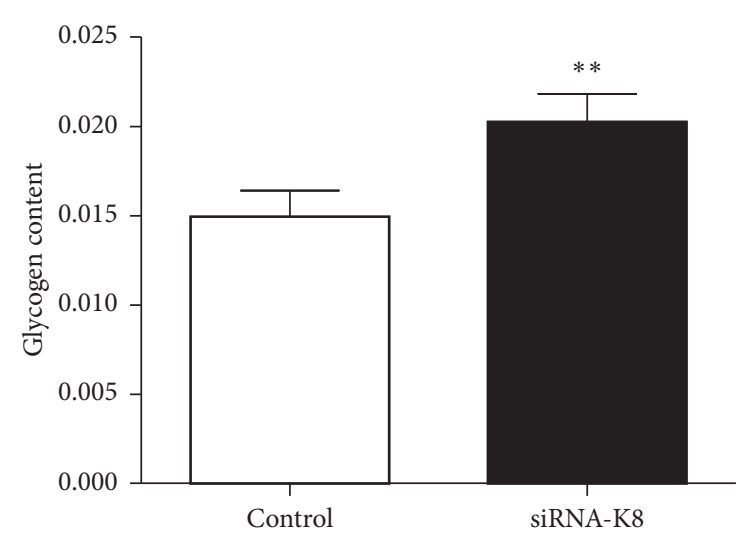

(b)

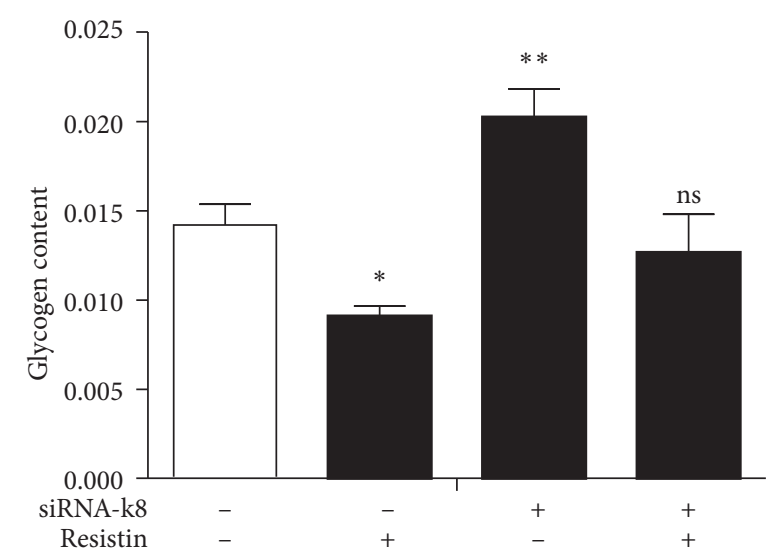

(c)

FIGURE 2: Resistin decreases glycogen biogenesis by regulating K8. HepG2 cells were transfected with K8 siRNA. The levels of keratin messenger (a) and the glycogen content (b) were determined. The cellular glycogen content was measured with or without resistin for $24 \mathrm{~h}$ after transfection with K8 (c). Data are presented as mean \pm SD. ${ }^{*} p<0.05$ and ${ }^{* *} p<0.01$. 


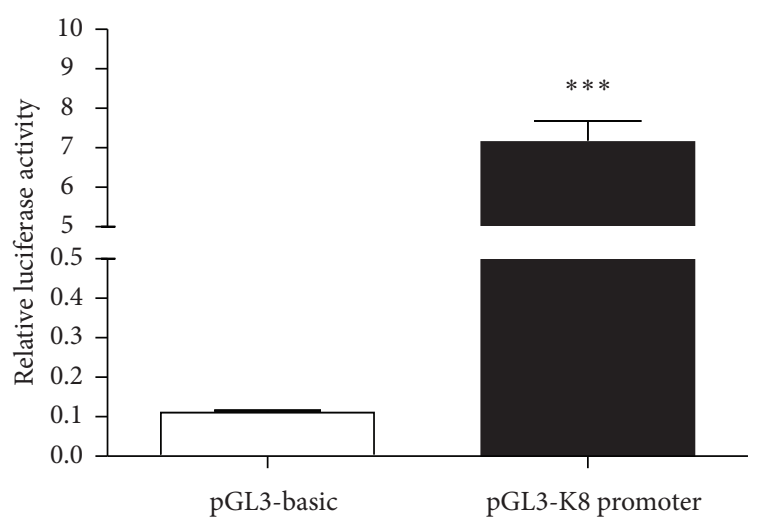

(a)

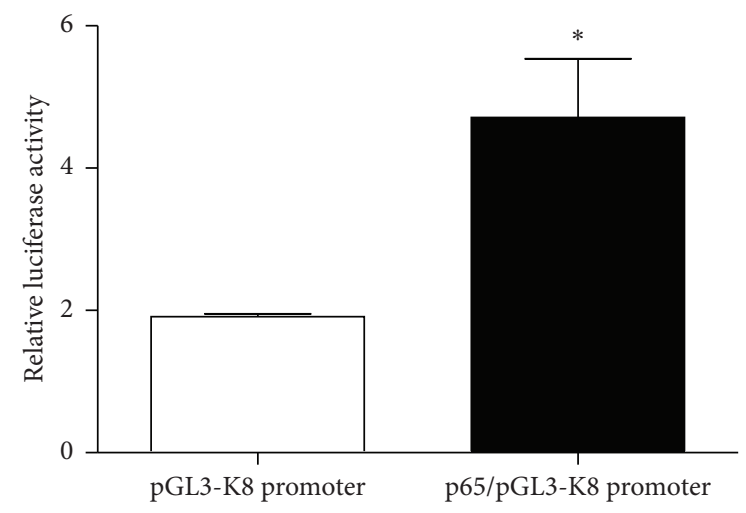

(c)

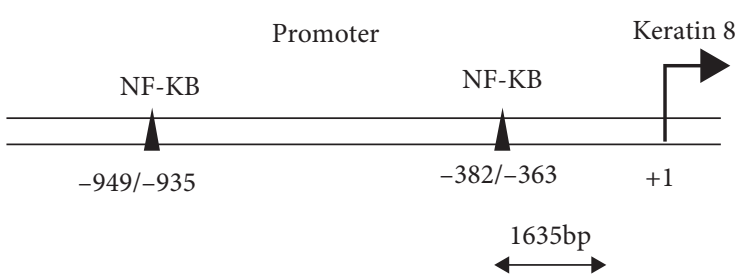

(b)

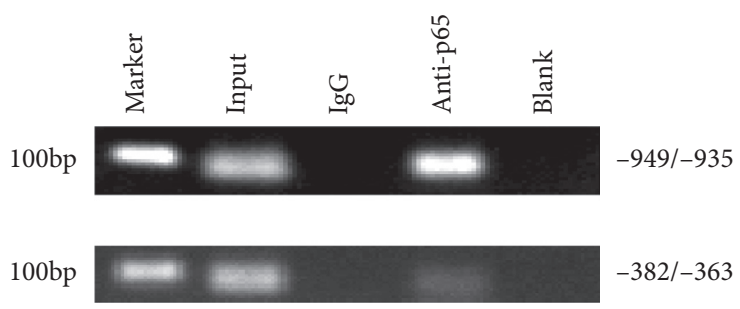

(d)

FIGURE 3: p65 binds directly to the K8 promoter. (a) The luciferase activity of the plasmid containing the pGL3-K8 promoter was greatly increased compared with that of control. (b) Schematic of the putative K8 promoter with two potential p65 response elements. (c) Luciferase assays in HEK293A cells. p65 significantly increased the luciferase activity of the vector containing the pGL3-K8 promoter. (d) Chromatin immunoprecipitation assays revealed that p65 interacts with the K8 promoter. Data are presented as mean \pm SD. ${ }^{*} p<0.05$ and ${ }^{* *} p<0.01$.

HepG2 cells with pcDNA3.1-p65/siRNA-p65 and siRNA-K8 alone or in combination, with or without treatment with resistin, and measured the glycogen content. The results showed that resistin regulated the glycogen content in a K8dependent manner (Figures 5(c) and 5(d)).

\section{Discussion}

As an important component of the cytoskeleton family, keratin has been widely studied since the 1970s [21-23]. However, early studies mainly focused on the structure and biological diversity of keratin instead of functional analysis. Although keratins are extensively used as biomarkers in the diagnosis of cancer [24], studies on their functions other than their role in maintaining structure are still rare. In recent years, keratins have been found to play key roles in cell apoptosis [24, 25], cell growth [26], and wound healing [27]. Deletion of K8/K18 in normal and cancerous mouse hepatic cells promotes insulin-mediated glucose uptake [28], suggesting that keratin plays a role in metabolism. The regulatory role of keratin in resistin-mediated glycogen accumulation is the basis of this study.

This study investigated the relationship between resistin and keratin 8 in the regulation of glucose metabolism. Glycogen accumulation in hepatic cells was inhibited by a wide range of resistin concentrations (from $25 \mathrm{ng} / \mathrm{mL}$, which is the concentration in normal individuals, to $200 \mathrm{ng} / \mathrm{mL}$, the concentration in diabetic patients), with significant inhibition occurring in response to lower resistin concentrations. Thus, in this study, we used a low level $(25 \mathrm{ng} / \mathrm{mL})$ of resistin to stay within the physiologically normal range. Several groups have reported a regulatory role of $\mathrm{K} 8 / 18$ in glucose metabolism; however, the specific mechanism has not yet been addressed. In this study, we found that resistin regulated glycogen accumulation in hepatic cells through $\mathrm{K} 8$, providing additional evidence of the role of keratin in glucose metabolism.

Many studies have demonstrated a relationship between resistin and inflammation. Human resistin stimulates the proinflammatory cytokines TNF- $\alpha$ and IL-12 in macrophages through an NF- $\kappa$ B-dependent pathway [29], while exogenous resistin promotes the dimerization of p50/p65 and its nuclear translocation. Resistin can also upregulate p65 mRNA expression and protein level $[30,31]$. We also confirmed that human resistin increased p65 expression in a dose-dependent manner [32] and that p65 overexpression substantially inhibited glycogen accumulation in HepG2 cells. However, the silencing of K8 significantly reversed the inhibition of glycogen accumulation induced by $\mathrm{p} 65$ overexpression, indicating that p65 could regulate cellular glycogen accumulation by directly controlling K8 transcriptional expression. Our findings 


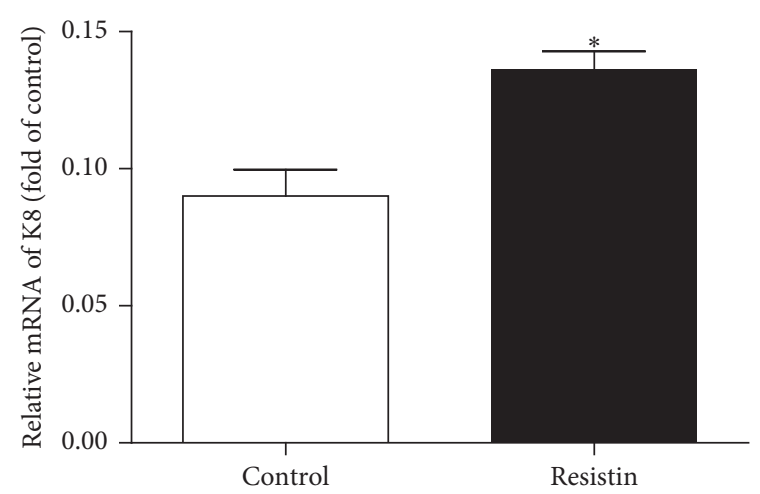

(a)

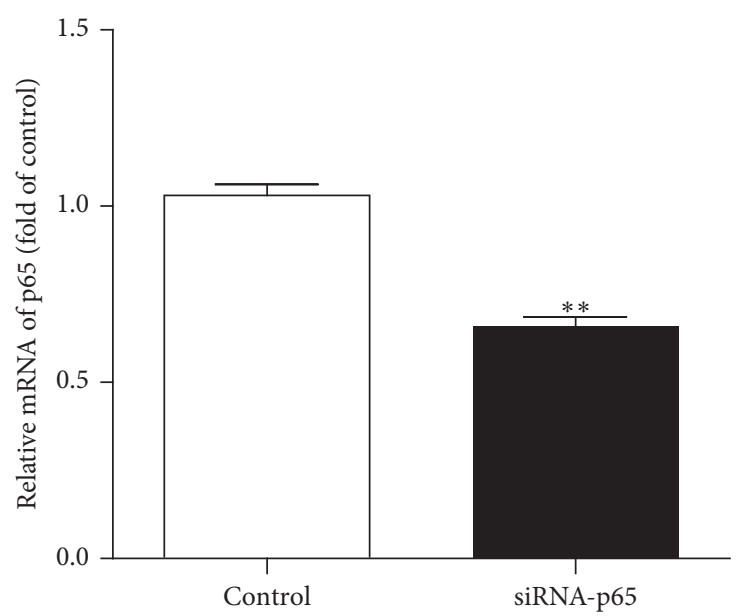

(c)

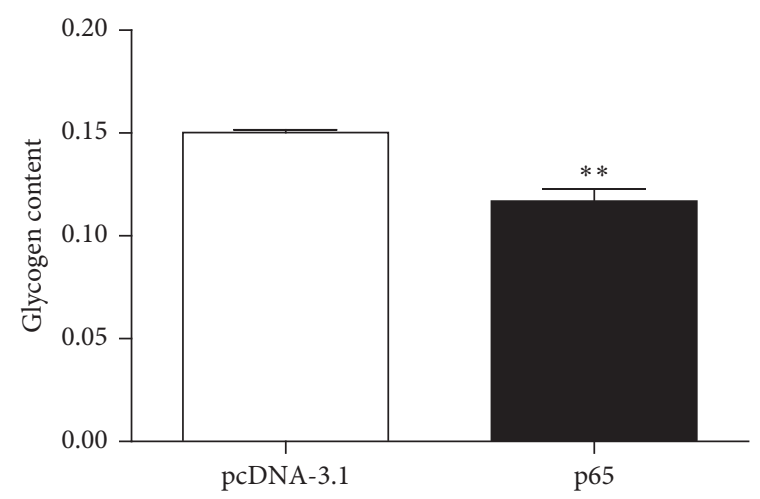

(e)

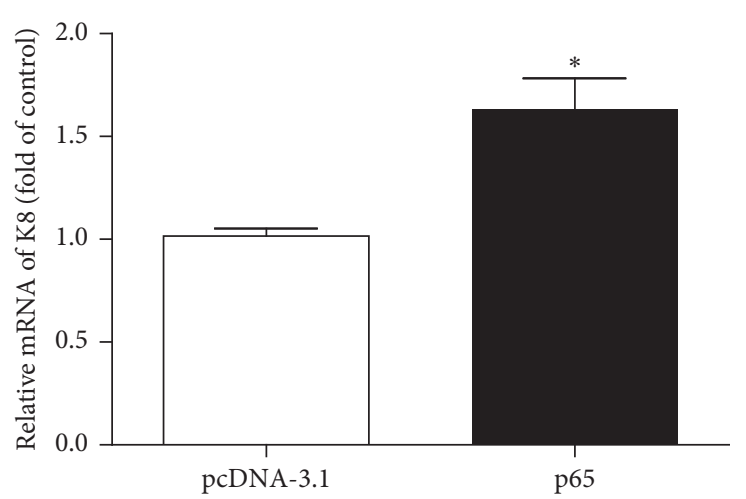

(b)

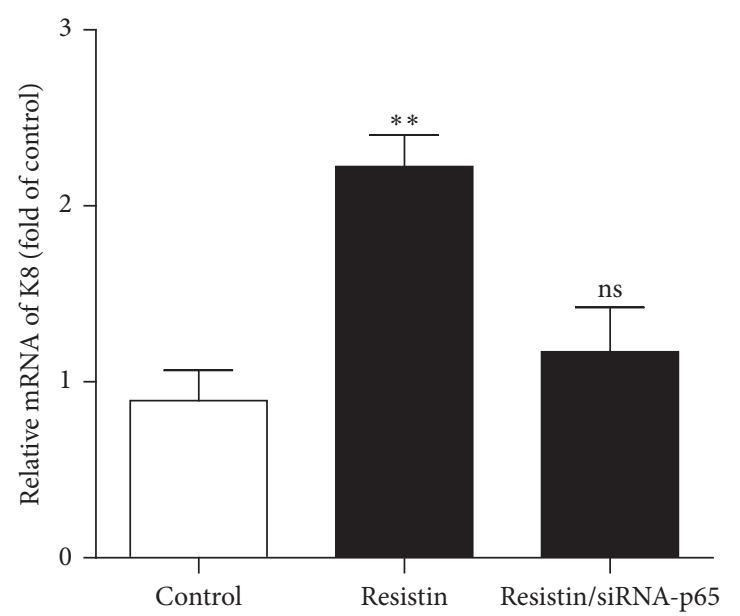

(d)

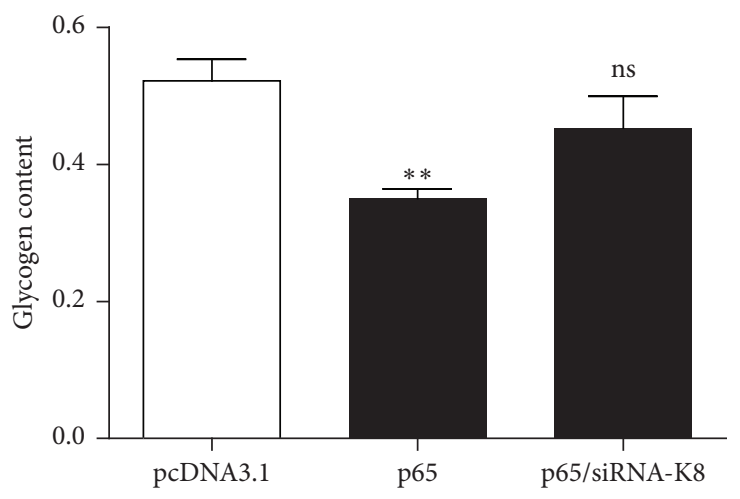

(f)

Figure 4: Resistin regulates K8 transcription through p65. (a) HepG2 cells were treated with or without resistin and K8 expression detected by using qRT-PCR. (b) HepG2 cells were transfected with a plasmid overexpressing p65 and K8 expression assessed by using qRT-PCR. (c) HepG2 cells were transfected with siRNA-p65 and p65 expression was determined by using qRT-PCR. (d) HepG2 cells were treated with or without resistin for $24 \mathrm{~h}$ after transfection with siRNA-p65, and K8 mRNA levels were determined by using qRT-PCR. (e) HepG2 cells were transfected with p65, and the glycogen content was determined after $24 \mathrm{~h}$. (f) HepG2 cells were cotransfected with K8 siRNA and the p65 expression plasmid, and the cellular glycogen content was measured after $24 \mathrm{~h}$. Data are presented as mean \pm SD. ${ }^{*} p<0.05$ and ${ }^{* *} p<0.01$.

confirm the relationship between resistin and inflammation through keratin and shed new light on the mechanism of resistin-mediated glycogen accumulation. Interestingly, although both resistin and p65 overexpression can decrease glycogen, we did not find superimposed effects with resistin and p65 in inhibiting glycogen content (Figure 5(c)). One possible explanation is that a supplementary mechanism exists, which maintains cellular homeostasis; such a mechanism remains to be verified.

Previous reports have suggested that K8 acetylation promotes perinuclear keratin filament organization [17]. Acetylation also modulates K8 site-specific phosphorylation, which regulates $\mathrm{K} 8$ solubility [17]. In vitro, glucose promotes $\mathrm{K} 8$ acetylation, while $\mathrm{K} 8$ acetylation itself has been found to be 


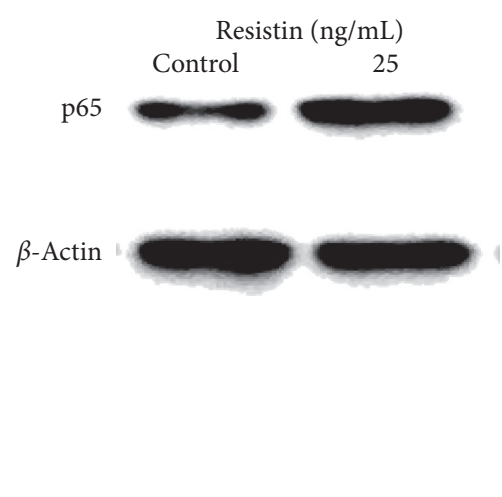

(a)

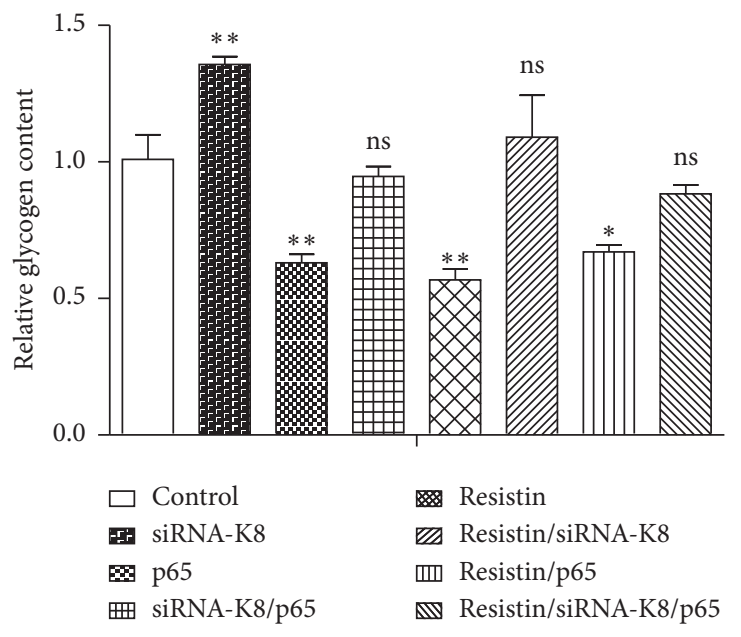

(c)

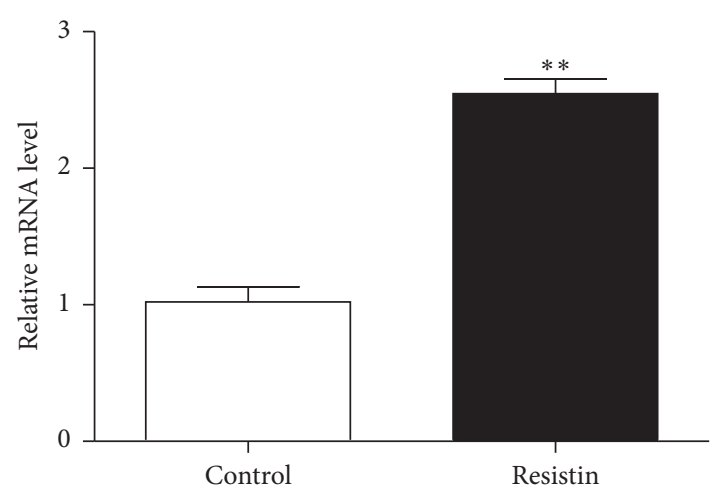

(b)

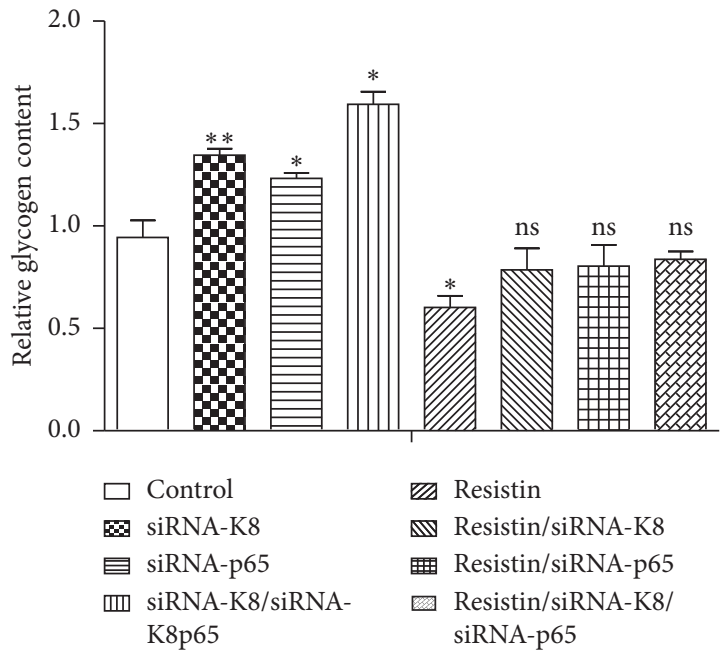

(d)

FIGURE 5: Resistin-regulated accumulation of glycogen through K8 involves p65. HepG2 cells were treated with human recombinant resistin protein, and the protein level (a) and mRNA level (b) of p65 were determined by using Western blot and qRT-PCR, respectively. (c) HepG2 cells were treated with or without resistin after cotransfection with K8 siRNA and p65 expression plasmid, and the glycogen content determined. (d) HepG2 cells were treated with or without resistin after cotransfection with K8 siRNA and p65 siRNA, and the glycogen content was determined. Data are presented as mean \pm SD. ${ }^{*} p<0.05$ and ${ }^{* *} p<0.01$.

increased in diabetic mice [28]. Resistin-induced inhibition of cellular glycogen accumulation is an outcome of multiple regulatory processes that vary under different physiological conditions. However, it is still not known if resistin affects K8 filament reorganization at the protein level or if filament reorganization plays a dominant role in the regulation of glycogen accumulation. The answers to these questions will help explain why resistin has multiple functions in glucose metabolism and facilitate the development of novel antidiabetic drugs.

In summary, we found that resistin upregulated p65 expression, while p65 promoted K8 transcriptional expression by directly binding to the $\mathrm{K} 8$ promoter, which inhibited cellular glycogen accumulation.

\section{Data Availability}

The data used to support the findings of this study are available from the corresponding author upon request.

\section{Conflicts of Interest}

No potential conflicts of interest relevant to this article were reported.

\section{Authors' Contributions}

Fengyun Wen and Qiao Xia contributed equally to this work. Zaiqing Yang conceived the presented idea. Qiao Xia designed the study and acquired data partially. Fengyun Wen contributed to research data, discussion, and drafted the manuscript. Hui Zhang and Haipeng Shi contributed to the animal experiments. Amin Rajesh provided critical revision. Yanling $\mathrm{Wu}$ and Yi Yang analyzed and interpreted the data. Zaiqing Yang is the guarantor of this work and, as such, had full access to all of the data in the study and takes responsibility for the integrity of the data and the accuracy of data analysis. 


\section{Acknowledgments}

This work was supported by the Program of National Natural Science Foundation of China (no. U1804118), Program of Henan Province Higher Education Key Teachers Training (no. 2018GGJS052), and Research Initiate Funds for PhD of Henan University of Science and Technology (no. 4025/13480073). The authors thank LetPub (https://www. letpub.com) for its linguistic assistance during the preparation of this manuscript.

\section{References}

[1] C. M. Steppan, S. T. Bailey, S. Bhat et al., "The hormone resistin links obesity to diabetes," Nature, vol. 409, no. 6818, pp. 307-312, 2001.

[2] D. B. Savage, C. P. Sewter, E. S. Klenk et al., "Resistin/Fizz3 expression in relation to obesity and peroxisome proliferatoractivated receptor- action in humans," Diabetes, vol. 50, no. 10, pp. 2199-2202, 2001.

[3] J. Vendrell, M. Broch, N. Vilarrasa et al., "Resistin, adiponectin, ghrelin, leptin, and proinflammatory cytokines: relationships in obesity," Obesity Research, vol. 12, no. 6, pp. 962-971, 2004.

[4] E. D. Muse, S. Obici, S. Bhanot et al., "Role of resistin in dietinduced hepatic insulin resistance," Journal of Clinical Investigation, vol. 114, no. 2, pp. 232-239, 2004.

[5] R. Song, X. Wang, Y. Mao et al., "Resistin disrupts glycogen synthesis under high insulin and high glucose levels by downregulating the hepatic levels of GSK3 $\beta$," Gene, vol. 529, no. 1, pp. 50-56, 2013.

[6] N.-O. Ku, S. Michie, E. Z. Resurreccion, R. L. Broome, and M. B. Omary, "Keratin binding to $14-3-3$ proteins modulates keratin filaments and hepatocyte mitotic progression," Proceedings of the National Academy of Sciences, vol. 99, no. 7, pp. 4373-4378, 2002.

[7] F. X. Bosch, R. E. Leube, T. Achtstätter, R. Moll, and W. W. Franke, "Expression of simple epithelial type cytokeratins in stratified epithelia as detected by immunolocalization and hybridization in situ," The Journal of Cell Biology, vol. 106, no. 5, pp. 1635-1648, 1988.

[8] C. Caulin, C. F. Ware, T. M. Magin, and R. G. Oshima, "Keratin-dependent, epithelial resistance to tumor necrosis factor-induced apoptosis," Journal of Cell Biology, vol. 149, no. 1, pp. 17-22, 2000.

[9] J. Mathew, A. Loranger, S. Gilbert, R. Faure, and N. Marceau, "Keratin 8/18 regulation of glucose metabolism in normal versus cancerous hepatic cells through differential modulation of hexokinase status and insulin signaling," Experimental Cell Research, vol. 319, no. 4, pp. 474-486, 2013.

[10] S. Bonin, D. Pracella, R. Barbazza, S. Sulfaro, and G. Stanta, "In stage II/III lymph node-positive breast cancer patients less than 55 years of age, keratin 8 expression in lymph node metastases but not in the primary tumour is an indicator of better survival," Virchows Archiv, vol. 466, no. 5, pp. 571-580, 2015.

[11] T. O. Helenius, J. O. Misiorek, J. H. Nyström et al., "Keratin 8 absence down-regulates colonocyte HMGCS2 and modulates colonic ketogenesis and energy metabolism," Molecular Biology of the Cell, vol. 26, no. 12, pp. 2298-2310, 2015.

[12] I. A. d. Santana, G. S. Moura, N. F. Vieira, and R. Cipolotti, "Metabolic syndrome in patients with prostate cancer," Sao Paulo Medical Journal, vol. 126, no. 5, pp. 274-278, 2008.
[13] P. Hillon, B. Guiu, J. Vincent, and J.-M. Petit, "Obesity, type 2 diabetes and risk of digestive cancer," Gastroentérologie Clinique et Biologique, vol. 34, no. 10, pp. 529-533, 2010.

[14] B. J. Schmitz-Dräger, G. Lümmen, E. Bismarck, and C. Fischer, "Metabolisches syndrom und prostatakarzinom," Der Urologe, vol. 52, no. 6, pp. 842-846, 2013.

[15] F. Cantiello, A. Cicione, A. Cicione, A. Salonia et al., "Association between metabolic syndrome, obesity, diabetes mellitus and oncological outcomes of bladder cancer: a systematic review," International Journal of Urology, vol. 22, no. 1, pp. 22-32, 2015.

[16] M. B. Omary, N. O. Ku, J. Liao et al., "Keratin modifications and solubility properties in epithelial cells and in vitro," Subcell Biochem, vol. 31, pp. 105-140, 1998.

[17] N. T. Snider, J. M. Leonard, R. Kwan, N. W. Griggs, L. Rui, and M. B. Omary, "Glucose and SIRT2 reciprocally mediate the regulation of keratin 8 by lysine acetylation," The Journal of Cell Biology, vol. 200, no. 3, pp. 241-247, 2013.

[18] L. Zhou, X. Yu, Q. Meng et al., "Resistin reduces mitochondria and induces hepatic steatosis in mice by the protein kinase $\mathrm{C} /$ protein kinase G/p65/PPAR gamma coactivator 1 alpha pathway," Hepatology, vol. 57, no. 4, pp. 1384-1393, 2013.

[19] F. Wen, J. Zheng, J. Yu et al., "Macrophage migration inhibitory factor in the regulation of myoblast proliferation and differentiation," Bioscience, Biotechnology, and Biochemistry, vol. 80, no. 7, pp. 1313-1320, 2016.

[20] C. H. Sheng, Z. W. Du, Y. Song et al., "Human resistin inhibits myogenic differentiation and induces insulin resistance in myocytes," BioMed Research International, vol. 2013, Article ID 804632, 8 pages, 2013.

[21] W. W. Franke and R. Moll, "Cytoskeletal components of lymphoid organs," Differentiation, vol. 36, no. 2, pp. 145-163, 1987.

[22] B. W. Jackson, C. Grund, E. Schmid, K. Bürki, W. W. Franke, and K. Illmensee, "Formation of cytoskeletal elements during mouse embryogenesis," Differentiation, vol. 17, no. 1-3, pp. 161-179, 1980.

[23] N. S. Fotakis, "On the problem of keratin formation in craniopharyngioma (Erdheim's tumor)," Acta Histochemica, vol. 12, pp. 12-25, 1961.

[24] J. Lee, K.-H. Jang, H. Kim et al., "Predisposition to apoptosis in keratin 8-null liver is related to inactivation of NF-kappaB and SAPKs but not decreased c-Flip," Biology Open, vol. 2, no. 7, pp. 695-702, 2013.

[25] N. Marceau, A. Loranger, S. Gilbert, N. Daigle, and S. Champetier, "Keratin-mediated resistance to stress and apoptosis in simple epithelial cells in relation to health and disease," Biochemistry and Cell Biology, vol. 79, no. 5, pp. 543-555, 2001.

[26] M. Knöbel, E. A. O’Toole, and F. J. D. Smith, "Keratins and skin disease," Cell and Tissue Research, vol. 360, no. 3, pp. 583-589, 2015.

[27] V. Usachov, T. J. Urban, R. J. Fontana et al., "Prevalence of genetic variants of keratins 8 and 18 in patients with druginduced liver injury," BMC Medicine, vol. 13, p. 196, 2015.

[28] J. Bártek, B. Vojtěšek, Z. Stašková et al., "A series of 14 new monoclonal antibodies to keratins: characterization and value in diagnostic histopathology," The Journal of Pathology, vol. 164, no. 3, pp. 215-224, 1991.

[29] N. Silswal, A. K. Singh, B. Aruna, S. Mukhopadhyay, S. Ghosh, and N. Z. Ehtesham, "Human resistin stimulates the proinflammatory cytokines TNF- $\alpha$ and IL-12 in macrophages by NF- $\kappa$ B-dependent pathway," Biochemical and Biophysical Research Communications, vol. 334, no. 4, pp. 1092-1101, 2005. 
[30] C. Y. Jiang, W. Wang, J. X. Tang et al., "The adipocytokine resistin stimulates the production of proinflammatory cytokines TNF-alpha and IL-6 in pancreatic acinar cells via NFkappaB activation," Journal of Endocrinological Investigation, vol. 36, pp. 986-992, 2013.

[31] J. Zhang, T. Lei, X. Chen et al., "Resistin up-regulates COX-2 expression via TAK1-IKK-NF- $\kappa$ b signaling pathway," Inflammation, vol. 33, no. 1, pp. 25-33, 2010.

[32] F. Wen, Y. Yang, D. Jin, J. Sun, X. Yu, and Z. Yang, "MiRNA145 is involved in the development of resistin-induced insulin resistance in HepG2 cells," Biochemical and Biophysical Research Communications, vol. 445, no. 2, pp. 517-523, 2014. 